\title{
Voltammetric Sensor Based on Electrodes Modified by Poly(vinyl alcohol)-Natural Clay Film, for the Detection of Gallic Acid
}

\author{
Hambate G. Valery, ${ }^{\text {a, }}{ }^{*}$ Abdelilah Chtaini ${ }^{b}$ and Benoît Loura ${ }^{a}$ \\ ${ }^{a}$ The Higher Institute of the Sahel, University of Maroua, Cameroon \\ ${ }^{b}$ Team of Molecular Electrochemistry and Inorganic Materials, Faculty of Sciences \\ and Technology of Beni Mellal, University of Sultan Moulay Slimane, Morocco
}

Received February 2, 2017; accepted October 2, 2018

\begin{abstract}
The aim of this study was to produce an inexpensive and easy to implement electrochemical sensor. The synthesis of a composite from poly (vinyl alcohol) and natural clay enabled to obtain a material with interesting properties, in view of the results achieved from thermal analysis and transmission electron microscopy. The layer film of natural poly (vinyl alcohol) clays was used to modify the glassy carbon electrode of which electrochemical response was good in the presence of gallic acid in a phosphate buffer solution. The mechanism of electro-oxidation reaction was proposed, and the $\mathrm{pH}$ effect has been approached in order to confirm the reaction mechanism. The concentration linearly increased with the oxidation current peak, with a regression coefficient of 0.989 and a detection limit of $1.005 \mu \mathrm{M}(\mathrm{S} / \mathrm{N}=3)$. The method thus proposed is satisfactory for the determination of gallic acid in a solution.
\end{abstract}

Keywords: Electrochemical sensor, glassy carbon electrode, electro-oxidation, detection limit.

\section{Introduction}

Gallic acid (3, 4, 5-trihydroxybenzoic acid) is a molecule with antioxidant properties [1-2]. It is therapeutic and it is used in traditional Chinese medicine, being also present in fruits such as bananas, citrus fruits, and tea. These compounds have captured great attention in recent years, due to both scavenging ability against free radicals and ready availability [3-5]. In addition to these antioxidant properties, gallic acid has anti-inflammatory properties, antihistaminic and antitumor activities, scavenging of free radicals and protection against cardiovascular diseases [6].

The synthesis of composite materials from polymers and clays has attracted the attention of many researchers because of their properties [7-8]. In order to develop new electrochemical sensors, many reports show the modification of an

\footnotetext{
* Corresponding author. E-mail address: v.hambategomdje@usms.ma
} 
electrode surface by coverage with a polymer/clay, and describe the electrochemical behavior of several substances incorporated into the clay film [914].

Poly (vinyl alcohol) (PVA) is a water-soluble polymer extensively used in paper coating, textile sizing, and flexible water-soluble packaging films [15]. PVA is a type of poly hydroxyl polymer that is broadly used as a bioactive material in tissue engineering. It has appropriate physicochemical properties for use as a coating, such as hydrophilicity and ease of film-formation, as well as good biocompatibility [16].

The application of silicates and related mineral materials in electrochemistry is rather recent, and it was directed to combine their intrinsic properties to select electrochemical reactions, in order to improve the electrodes response. Modified electrodes are being frequently used in the voltammetric determination of organic compounds, because of their efficiency, the selectivity that can be obtained by varying the modifier and the sensitivity, which is equivalent to that reached in anodic and cathodic stripping. In doing so, zeolithe and silica modified electrodes were prepared, characterized and applied in various fields including, for example, electro analysis and sensors, electro catalysis, photochemistry, thin-film technology, fuel cells and molecular recognition [17]. Over the years, various methods have been applied for the determination of gallic acid, such as flow injection analysis [18-19], resonance light scattering [20], thin layer chromatography [21] and electrochemical methods [22-23]. Due to the pharmacological importance of GA, there is a need for a better analytical method for its determination with good selectivity and sensitivity.

In this paper, we prepared an electrochemical sensor based on a glassy carbon electrode modified by a film composite material based on poly (vinyl alcohol) and the natural clay of Maroua (Cameroon). Differential scanning calorimetry (DSC) and transmission electron microscopy (TEM) were used to characterize the composite. The application for the detection of gallic acid in a buffer solution was carried out.

\section{Materials and methods}

\section{Chemical reagents and equipment}

Gallic acid was purchased from Sigma-Aldrich. Poly(vinyl alcohol) was obtained from Fine-Chem limited (India) ( $\geq 99.0 \%$ ). Potassium phosphate monobasic (99\%), sodium hydroxide and chloridric acid were purchased from Sisco Research Laboratories pvt. Ltd, India.

Differential scanning calorimetry (DSC) was recorded using a SDT Q600 V8.3 Build 101 simultaneous DSC-TGA instrument. Transmission electron micrographs of composites were taken with a Tecnai F20 (FEI) transmission electron microscope, with an accelerating voltage of $200 \mathrm{kV}$. Cyclic voltammetry $(\mathrm{CV})$ of all prepared GCE/PVA/natural clays, as well as unmodified GCE were performed on a CHI 6084C electrochemical analyzer (USA). A three electrode measurement cell equipped with Poly (vinyl alcohol)-natural clays/GCE (working electrode), an $\mathrm{Ag} / \mathrm{AgCl}$ (saturated $\mathrm{KCl}$ ) reference electrode 
and a Pt wire auxiliary electrode were used for all measurements. A phosphate buffer solution $0.1 \mathrm{M}(\mathrm{pH}=6.8)$ was used as electrolyte solution.

\section{Preparation of poly(vinyl alcohol)/clays composites}

The Maroua clay was purified by a method described in the literature [24]. Its cation exchange capacity was $63 \mathrm{meq} / 100.10 \mathrm{~g}$ of poly(vinyl alcohol) were added to $40 \mathrm{~g}$ of purified clay, and the mixture was homogenized in an aqueous solution with stirring at $1500 \mathrm{rpm}$ for $30 \mathrm{~min}$, and then subjected to probe ultrasonication. The mixture was then maintained at $70{ }^{\circ} \mathrm{C}$ for 1 hour.

\section{Preparation of working electrode}

The poly(vinyl alcohol)-natural clays modified electrodes were prepared using the glassy carbon electrode (GCE). GCE was previously polished with aqueous suspension alumina slurries of different sizes $(1$, then $0.05 \mu \mathrm{m})$ on a billiard cloth, and ultrasonically cleaned for $10 \mathrm{~min}$ in acetone, then rinsed with distilled water and dried at room temperature. The thin poly(vinyl alcohol)-natural clays film working electrode was prepared by "drop coating" $10 \mu \mathrm{L}$ of the aqueous dispersion of poly(vinyl alcohol)- natural clays on the active surface (3 $\mathrm{mm}$ in diameter) of the GCE. The modified electrodes were stored at oven at $50{ }^{\circ} \mathrm{C}$ for 2 $\mathrm{h}$, to ensure they were completely dried before use.

\section{Results and discussions}

\section{Thermal analysis (differential scanning calorimetry-DSC)}

Fig. 1 shows the DSC with heat transfer measurements. This figure shows an important exothermic peak around $422.41{ }^{\circ} \mathrm{C}$, corresponding to the crosslinking of the PVA on the surface of the clay. Another characteristic peak around $300{ }^{\circ} \mathrm{C}$ indicates that the PVA on the surface of the clay degraded. The last peak around $500{ }^{\circ} \mathrm{C}$ was due to recrystallization.

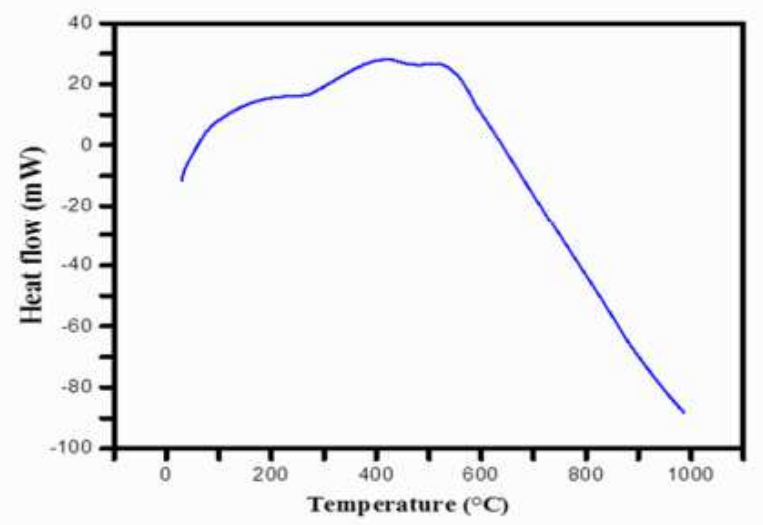

Figure 1. Differential scanning calorimetry of poly(vinyl alcohol)-natural clay.

\section{Morphology analysis of film modified clay}

The surface morphology of the modified clay (see Fig. 2) clearly shows its dispersion into the polymer matrix. The superimposed layers in the form of a well-ordered stack are observable characteristics of the clay. 


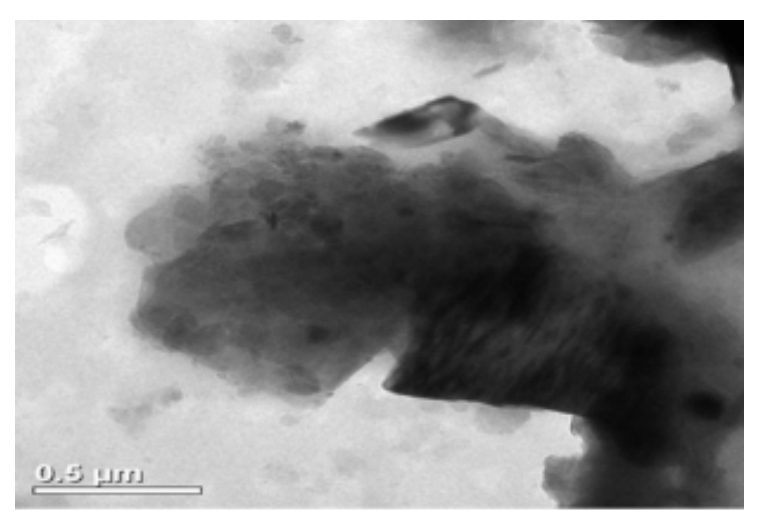

Figure 2. Poly(vinyl alcohol)-natural clay.

Figs. $3 \mathbf{a}$ and $\mathbf{b}$ show images of TEM at low and high magnification of the modified clay. In these figures, the observed different interfoliar layers of the clay with black bands justify its nanostructures (Fig. 3a). On the contrary, on the high-magnification image of the modified clay, the presence of a thin layer of polymer covering clay is observable, which explains its compatibility with the polymer (Fig. 3b).
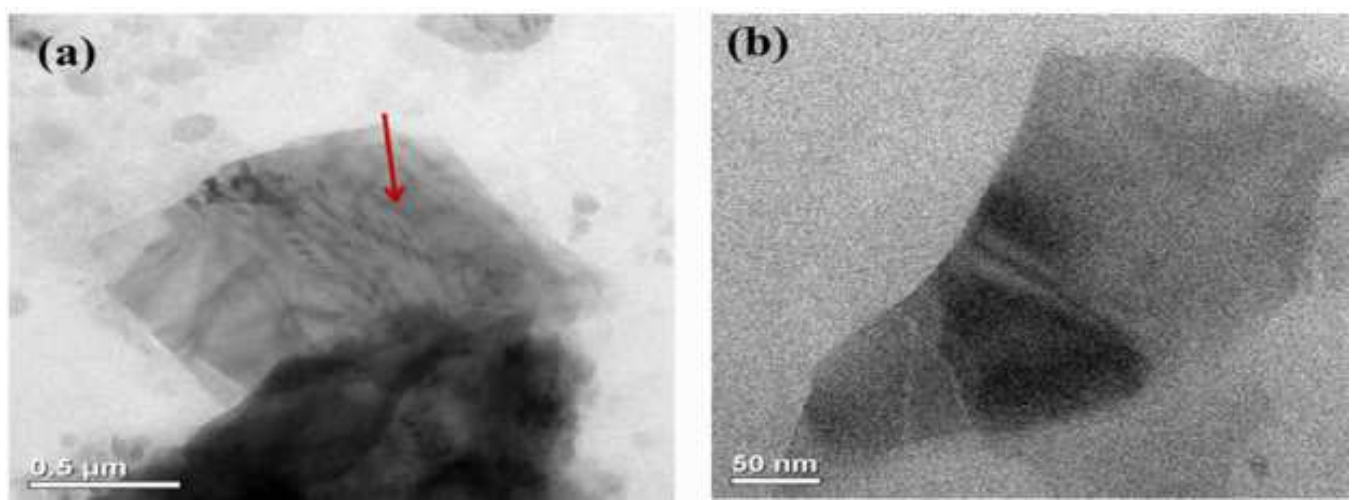

Figure 3. TEM image of poly(vinyl alcohol)-natural clay film at different magnifications.

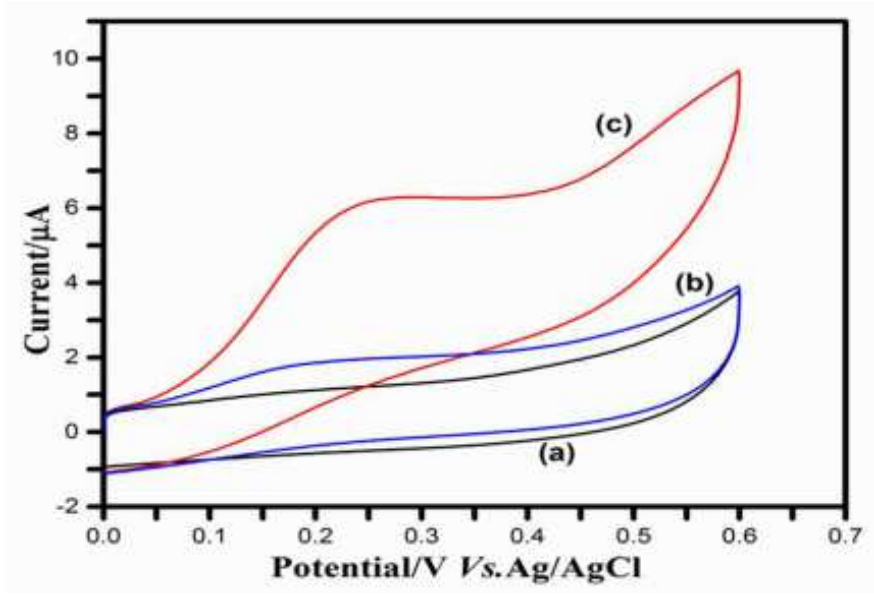

Figure 4. Cyclic voltammograms (CVs) of (a) bare GCE in the absence of gallic acid (GA), (b) bare GCE in the presence of $250 \mu \mathrm{M}$, and (c) GCE modified with ploy(vinyl alcohol)-natural clays in the presence of $250 \mu \mathrm{M}$, in a phosphate buffer solution $(\mathrm{pH}=6.4)$ at $50 \mathrm{mVs}^{-1}$. 


\section{Electrochemical detection of gallic acid}

\section{Electrochemical behavior of gallic acid}

The cyclic voltammograms in Fig. 4 show that the electrode modified by the thin layer of poly(vinyl alcohol)-natural clays exhibits a good response, which is manifested by an oxidation current peak at $6.13 \mu \mathrm{A}$ and an oxidation potential at $0.245 \mathrm{~V}$, characteristic of electrochemical data for gallic acid oxidation. The peak of reduction does not seem to be too observable.

Compared to the cyclic voltammogram of the carbon bare electrode, the response of the oxidation peak is not very pronounced (the oxidation peak current is 1.848 $\mu \mathrm{A}$, although the amount of gallic acid was the same), which means that the modified glassy carbon electrode is sensitive to the electro-oxydation of gallic acid, according to the following scheme:

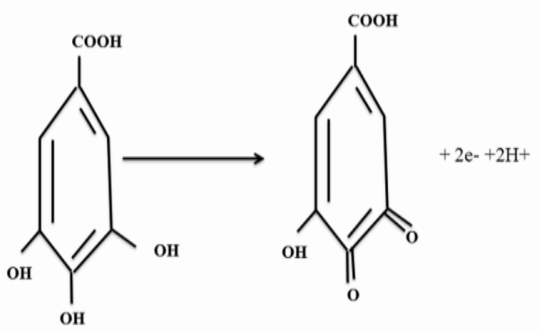

Scheme 1. Mechanism of oxidation of gallic acid.

At the $\mathrm{pH}$ range of 2.5 to 7.4 , the oxidation peaks linearly increased with the $\mathrm{pH}$ (Fig. 5), with a slope of $54.23 \mathrm{mV}$ per unit of $\mathrm{pH}$. This value effectively corresponds to the proposed mechanism, with two electrons exchanged.

\section{Calibration straight}

Fig. 6 shows the cyclic voltammograms at different concentrations of the gallic acid, in the range from 100 to $800 \mu \mathrm{M}$. The oxidation current peak increases with the concentrations, giving a regression coefficient of 0.989 , being the limit detection $1.005 \mu \mathrm{M}$.

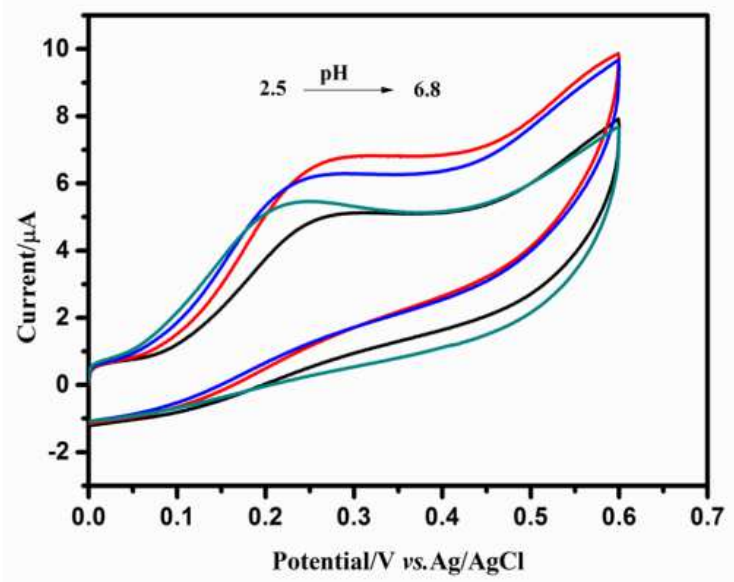

Figure 5. CVs of glassy carbon electrode modified with ploy(vinyl alcohol)-natural clays in the presence of $250 \mu \mathrm{M}$ at different $\mathrm{pH}$ values $(2.5,3.8,4.5,6.8)$, in a phosphate buffer solution $(\mathrm{pH}=6.4)$ at $50 \mathrm{mVs}^{-1}$. 

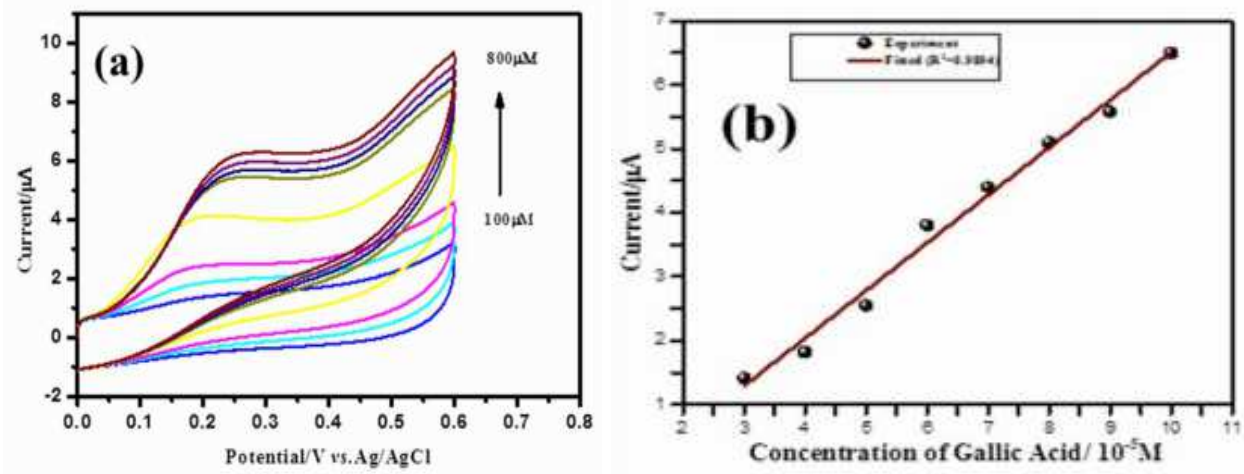

Figure 6. (a) CVs response of glassy carbon electrode modified with poly(vinyl alcohol) at different added concentrations of GA in a phosphate buffer solution; (b) plot of oxidation peak versus GA concentration.

\section{Conclusions}

This study made it possible to design an electrochemical sensor based on a film of composite materials composed of the natural clay of Maroua (Cameroon) and of an organic polymer: poly(vinyl alcohol). A composite material with interesting properties which was used for the detection of gallic acid enabled to have an electrochemical response, a good sensitivity and a low detection limit. This is a simple and low tool based on a mixture of inorganic and organic materials that can be used to evaluate the antioxidant power of compounds.

\section{Acknowledgements}

This work was financially supported by The World Academy of Sciences for the Advancement of Science in developing countries (TWAS) and the Council of Scientific and Industrial Research (CSIR). We thank also Dr.Vijayamohanan K Pillai, Director of Central Electrochemical Research Institute (CECRI) of Karaikudi, Tamilnadu (India), who gave us all the facilities to carry out our research.

\section{References}

1. Gali H, Perchellet EM, Klish DS, et al. Int J Cancer. 1992;51:425.

2. Hsu JD, Kao SH, Ou TT, et al. J Agric Food Chem. 2011;59:1996-2003.

3. Ghaani M, Nasirizadeh N, Yasini SA, et al. Anal Methods. 2016;8:1103.

4. Rajalakshmi, Naraimban S, Madhavi DL, et al. Food Antioxidants. 1996;65:157.

5. Lopez-Velez M, Martinez-Martinez F, Valle-Ribes CD. Crit Rev Food Sci. 2003;43:233.

6. Mudnic I, Modun D, Rastija V, et al. Food Chem. 2010;19:1205-1210.

7. Fotiadou S, Karageorgaki C, Chrissopoulou K, et al. Macromolecules. 2013;46:2842-2855.

8. Paul DR, Robeson LM. Polymer. 2008;49:3187-3204.

9. Ghosh PK, Bard AJ. J Am Chem Soc. 1983;105:5691-5693. 
10. Bard AJ, Malllouk T, Murray RW. editors. New York:WilleyInterscience; 1992, p. 271-312

11. Merz A, Bard AJ. J Am Chem Soc. 1978;100:3229.

12. Wrighton MS, Palazzotto MC, Bocarsly AB, et al. J Am Chem Soc. 1978;100:7264.

13. Brown AP, Anson FC. Anal Chem. 1977;49:1589.

14. Ghosh PK, Spiro TG. J Am Chem Soc. 1980;102:5543.

15. Strawhecker KE, Manas E. Chem Mater. 2000;12: 2943.

16. Mei L, Hai-han Z, Tao L, et al. Regen Research. 2015;10:2048-2053.

17. Walcarius A. Electroanalysis. 1996;8:971-986.

18. Shifeng L, Sun H, Wang D, et al. J Chem. 2012;30:837-841.

19. Xiang-Qin L, Feng L, Yong-Qiang P, et al. Anal Bioanal Chem. 2004;378:2028.

20. Andreu-Navarro A, Fernández-Romero JM, Gómez-Hens A. Anal Chim Acta. 2011;695:11-17.

21. Dhalwal K, Shinde VM, Biradar YS, et al. J Food Composit Analysis. 2008;21:496-500.

22. Abdel-Hamid R, Newair EF. J Electroanal Chem. 2013;704:32-37.

23. Ghoreishi SM, Behpour M, Khayatkashani M, et al. Anal Methods. 2011;3:636-645.

24. Tributh H, Lagaly G. GIT Fachz Lab. 1986;30:524-529. 